\title{
Scanning Electrochemical Microscopy Assessment of Rates of Molecular Transport through Mesoporous Thin-Films of Porphyrinic "Molecular Squares"
}

\author{
Mary Elizabeth Williams and Joseph T. Hupp* \\ Department of Chemistry and Center for Nanofabrication and Molecular Self-Assembly, \\ Northwestern University, Evanston, Illinois 60208
}

Received: March 8, 2001; In Final Form: July 14, 2001

\begin{abstract}
Scanning electrochemical microscopy (SECM), in combination with electrode platform micropatterning, has been used for qualitative characterization of molecular sieving and exceptionally precise quantitative measurement of molecular permeation through thin films of meso- and microporous materials composed of porphyrinic "molecular squares". SECM measurements reveal that modification of the squares, to reduce cavity sizes and alter the size cutoff for permeation, has only a modest effect upon the permeabilities of those probe molecules small enough to pass through the modified films. Additional experiments as a function of electrolyte composition show that the ability to observe sieving behavior electrochemically is determined not only by the relative sizes of redox-active permeant molecules and film-based cavity openings, but also by the steric properties of ions needed for charge compensation - even when the permeant molecule is initially neutral. As expected, when the size of the opening is altered the steric requirements for the charge-compensating ion are similarly altered. The experiments also show that charge-compensating ion transport can be convoluted to a small but measurable extent with the probe-molecule transport measurement. The identity of the component of the electrolyte not required for charge compensation, however, does not detectably affect the SECM-based permeation measurement.
\end{abstract}

Over the past decade an enormous number of new compounds based on supramolecular coordination chemistry, and featuring well-defined nanoscale and smaller cavities, have been synthesized. ${ }^{1} \mathrm{X}$-ray crystallographic measurements typically show that cavities are aligned in the solid state such that semi-infinite onedimensional channels are formed. We reasoned that compounds consisting of charge-neutral assemblies of this kind, lacking potentially channel-blocking counterions, would comprise an exceptionally interesting new class of micro- and mesoporous materials. These materials might well be expected, for example, to possess useful molecular recognition and sensing properties and unusual selective chemical transport properties. ${ }^{2}$ In addition, by analogy to zeolites, the materials may prove useful for catalytic chemistry - albeit, at much lower temperatures than typically used with zeolitic materials.

One of the more versatile members of the existing library of meso- and microporous molecular compounds is the neutral, Zn porphyrin based "molecular square", I, shown in Figure $1 .^{3}$ The Re-Re separation distance defined by the porphyrin walls is $20 \AA$, making it one of the larger available molecular squares. In Figure 1, the porphyrin square has been drawn so that the details of the structure are visible; in the solid state, the ligands define a cavity that is ca. $18 \times 18 \AA$. We have utilized the known ability of the $\mathrm{Zn}$ (II) sites to coordinate additional ligands axially thereby usefully modifying the size, ${ }^{3,4}$ shape,${ }^{3}$ chirality, ${ }^{4}$ hydrophobicity, ${ }^{5}$ and molecular and ionic guest binding properties $^{6}$ of the cavity. ${ }^{7}$ Among the more than 100 ligands that have been incorporated into the square are the dipyridyl porphyrin $\left(\mathrm{H}_{2} \mathrm{DPyP}\right)$ and $\mathrm{Zn}$ tetrapyridyl porphyrin (ZnTPyP) species shown in Figure 1. These are capable of coordinating to two and four $\mathrm{Zn}$ porphyrin walls, respectively. Space-filled diagrams

† Part of the special issue "Royce W. Murray Festschrift". of the resulting supramolecular assemblies, II and III, are shown in Figure 2. The formation of II and III converts the single large cavity of the parent square into two $8 \times 18$ and four 4.5 $\times 4.5 \AA$ cavities, respectively, thereby changing the size cutoff for molecular permeation of thin films of the square. ${ }^{3 \mathrm{~b}}$

Electrochemical measurements, using redox-active probe molecules and employing electrodes as platforms for thin-film fabrication, have proven to be an excellent means for assessing condensed-phase molecular sieving by these materials. ${ }^{3 b, 8}$ Cyclic voltammetry $(\mathrm{CV})$ has been used to obtain qualitative information about sieving, while rotating disk electrode (RDE) voltammetry has been employed successfully in semiquantitative sieving-rate studies. ${ }^{3 \mathrm{~b}}$ Film or membrane transport rates can influence sensor response times, chemical separation times, and catalysis rates, so are of clear importance in the context of applications of these materials. A drawback to conventional CV and RDE techniques, however, is that they report an ensemble average response for the film as a whole. Local variations in transport rate, due to variations in film thickness or other properties, are missed, while problems associated with pinhole defects, even if limited to a very small area of the film, sometimes distort the measured responses. ${ }^{3 \mathrm{~b}}$ We have recently turned to a more sophisticated technique, ${ }^{9}$ scanning electrochemical microscopy (SECM), employing it in a proof-ofconcept study involving simultaneous topographical imaging and molecular transport through a model thin-film material consisting of an amorphous metallopolymer. ${ }^{10}$ SECM is a remarkably versatile experimental approach, having been applied previously to transport and related problems, ranging from ion and electron transfer across liquid-liquid interfaces ${ }^{11}$ to iontophoretic transport across biomembranes ${ }^{12}$ and deposition of metals. ${ }^{13}$

Here we describe the application of SECM to the problem of size-selective molecular transport through mesoporous thin 


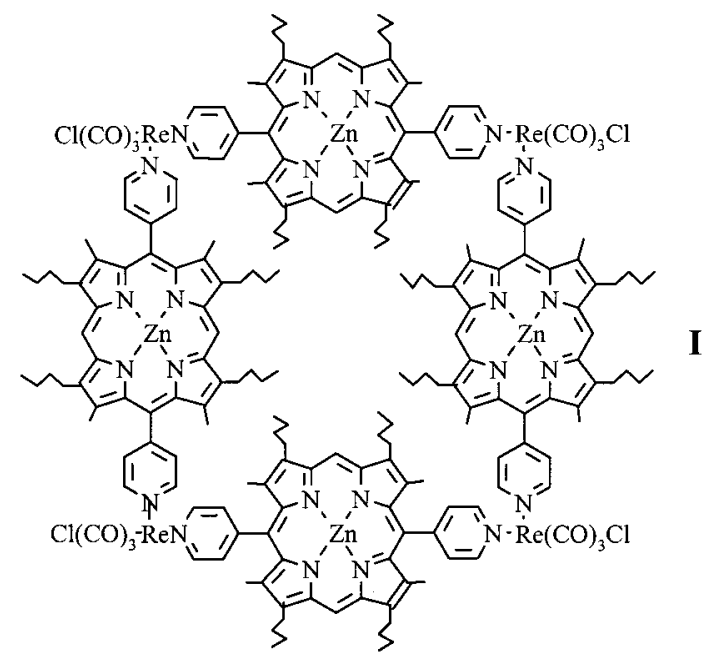

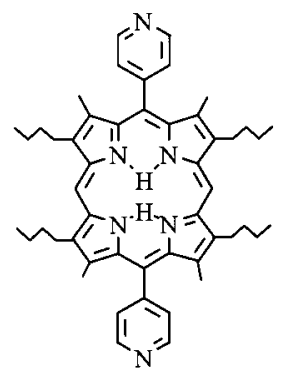

$\mathrm{H}_{2}$ DPyP

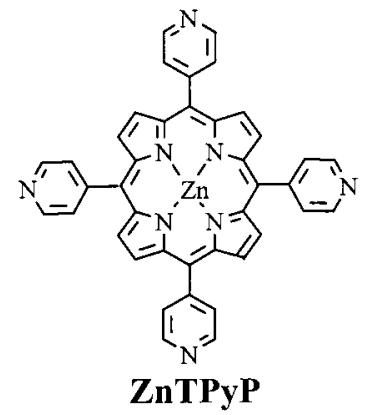

ZnTPyP
Figure 1. Structure of the porphyrin square, I (i.e., $\left[\operatorname{Re}(\mathrm{CO})_{3} \mathrm{Cl}(3,7\right.$, 13,17-tetramethyl-2,8,12, 8-tetra(n-butyl)-5,15-(4-pyridyl) Zn(II) porphyrin) $]_{4}$ ), and the ligands 3,7,13,17-tetramethyl-2,8,12, 8-tetra( $n$-butyl)5,15-(di-4-pyridyl) porphyrin $\left(\mathrm{H}_{2} \mathrm{DPyP}\right)$ and 1,5,10,15-tetra(4-pyridyl) $\mathrm{Zn}$ (II) porphyrin (ZnTPyP).

films of $\mathbf{I}$. We find that SECM is capable of providing exceptionally precise measures of transport rate parameters. We also report quantitative transport data for thin films composed of chemically modified squares, II and III, featuring cavity openings of much smaller size. Finally, we show that the ability to observe sieving behavior electrochemically is determined not only by the relative sizes of redox-active permeant molecules and film-based cavity openings but also by the steric properties of ions needed for charge compensation.

\section{Experimental Section}

Chemicals. Samples of 3,7,13,17-tetramethyl-2,8,12,8-tetra(n-butyl)-5,15-(di-4-pyridyl) $\mathrm{Zn}$ (II) porphyrin and the porphyrin square ([fac- $\operatorname{Re}(\mathrm{CO})_{3} \mathrm{Cl}(3,7,13,17$-tetramethyl-2,8,12, 8-tetra(n-butyl)-5,15-(4-pyridyl)Zn(II)porphyrin) $]_{4}$ ) were kindly donated by Katherine Splan and Melissa Merlau of Northwestern University. Their synthesis has been described previously. ${ }^{3 a}$ $\mathrm{Na}_{4}\left[\mathrm{Fe}\left(\text { bphen }\left(\mathrm{SO}_{3}\right)_{2}\right)_{3}\right]$ (bphen = 4,7-diphenyl-1,10-phenanthroline) was prepared by mixing three equivalents of $\mathrm{Na}_{2}$ [bphen $\left(\mathrm{SO}_{3}\right)_{2}$ ] (Aldrich; mix of meta and para sulfonated isomers) with one equivalent of $\mathrm{FeCl}_{2} \cdot 6 \mathrm{H}_{2} \mathrm{O}$ in water. The resulting dark red solution was concentrated, and the product precipitated with acetone. To remove traces of free ligand and $\mathrm{NaCl}$, the $\mathrm{Na}_{4}\left[\mathrm{Fe}\left(\text { bphen }\left(\mathrm{SO}_{3}\right)_{2}\right)_{3}\right]$ was dialyzed for 7 days with 1000 molecular weight cutoff dialysis tubing (SpectraPor) in continuously exchanged water. The product was recrystallized with water/acetone and dried in a vacuum oven overnight. All other chemicals were reagent grade and used as received. Ultrapure (18.1 M $\Omega$ ) water (Millipore) was exclusively used in SECM experiments.

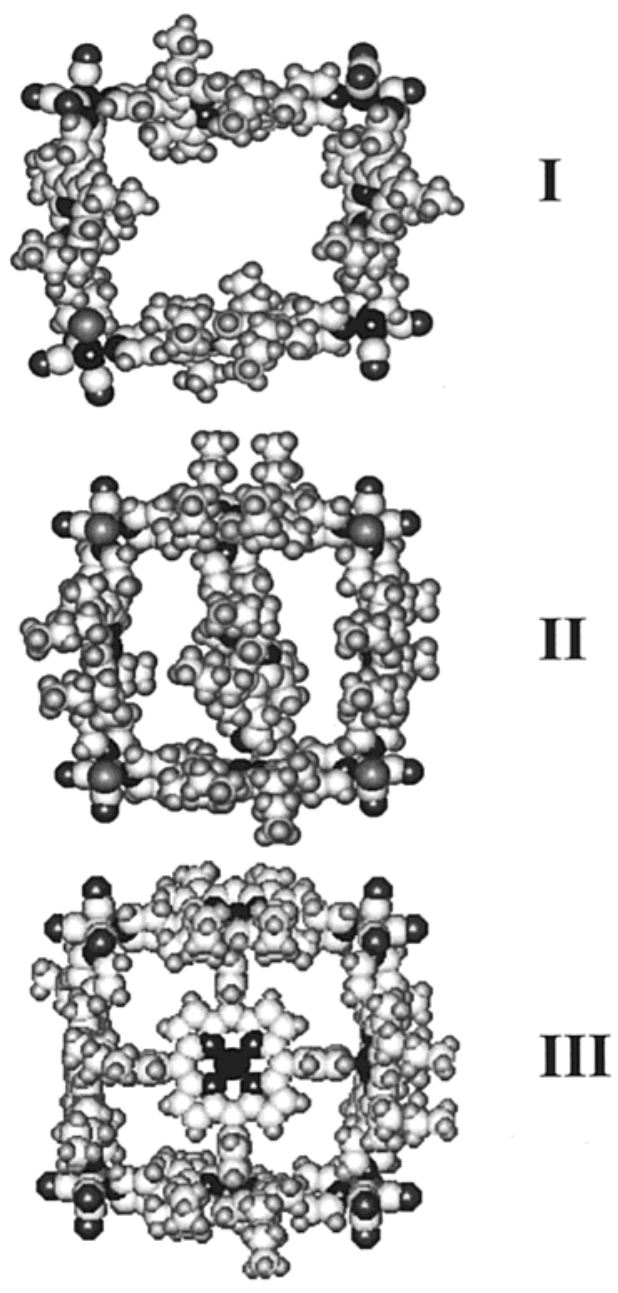

Figure 2. Space-filled diagrams of the porphyrin square (I), the square with encapsulated $\mathrm{H}_{2}$ DpyP (II), and the square with encapsulated ZnTPyP (III).

Supramolecular species II and III were prepared by mixing equimolar amounts of porphyrin square I with the desired ligand $\left(\mathrm{H}_{2} \mathrm{DPyP}\right.$ or ZnTPyP) in chloroform. Electronic absorption spectra confirmed complexation of the fifth porphyrin ligand, consistent with previous observations. ${ }^{3}$

Electrochemical Measurements. A CH Instruments (Austin, TX) model 900 scanning electrochemical microscope (SECM) was used for all electrochemical experiments. All potentials are reported versus an SCE reference electrode. SECM microelectrode tips were prepared as previously described ${ }^{10}$ using 8 $\mu \mathrm{m}$ diameter carbon fibers (Alfa Aesar) sealed in a glass capillary, electrically connected to tungsten wire using conductive silver epoxy (Grace Specialty Products), and insulated by electropolymerization of 2-allylphenol. ${ }^{14}$ The electrode tips were freshly cleaved with a razor blade prior to each experiment, and the electroactive radius determined ${ }^{15}$ using an aqueous ferrocenemethanol ( $\mathrm{FcMeOH}$, Aldrich) solution of known concentration.

Indium tin oxide (ITO) coated glass slides (Delta Technologies) were micropatterned by Aaron Massari of Northwestern University as described previously. ${ }^{10}$ Briefly, a regular array of $50 \times 50 \mu \mathrm{m}$ ITO holes, separated by $50 \mu \mathrm{m}$ of an insulating photoresist layer (Shipley 1822), was created photolithographically. Films of the desired molecular square material were evaporatively cast (typically by spin-coating to achieve uniformly thick films) from chloroform and allowed to dry for at least $30 \mathrm{~min}$ prior to imaging. Film thicknesses were determined 

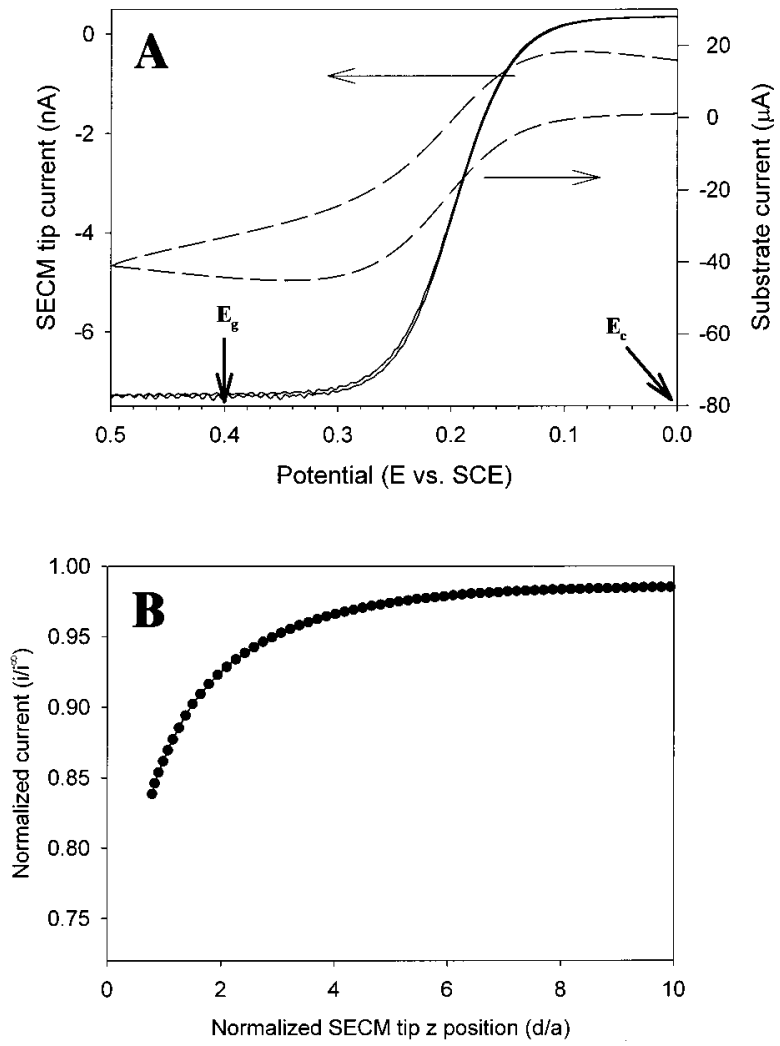

Figure 3. (A) Cyclic voltammograms of $2 \mathrm{mM} \mathrm{FcMeOH}$ using the 4 $\mu \mathrm{m}$ radius SECM carbon fiber tip electrode and an ITO platform containing a $52 \mathrm{~nm}$ thick film of $\mathbf{I}$ (exposed area is ca. $1 \mathrm{~cm}^{2}$ ). The potential scan rate is $50 \mathrm{mV} / \mathrm{s}$. (B) SECM tip approach curve obtained in the same cell, based on $E_{\text {tip }}=0.5 \mathrm{~V}$ and $E_{\text {plat }}=0 \mathrm{~V}$ vs SCE and an approach rate of $2 \mu \mathrm{m} / \mathrm{s}$. The tip current is normalized to the limiting current $\left(i / i^{\infty}\right)$, and the height above the surface $(d)$ is normalized to the tip radius, $r$.

as before ${ }^{3,8}$ using UV-visible spectroscopy and the known molar extinction coefficient of the compound. In some cases, film thicknesses were confirmed via cross-section analyses of tapping mode atomic force microscopy images obtained with a Digital Instruments Multimode Nanoscope IIIa. The AFM tips employed are single etched silicon (TESP) nanoprobe SPM tips (cantilever length $125 \mu \mathrm{m}$ and resonance frequency 307-367 $\mathrm{Hz}$, Digital Instruments). During sequential imaging experiments, the films were rinsed copiously and then soaked (for a minimum of $15 \mathrm{~min}$ ) with water to remove any ions or reagents from previous redox solutions.

\section{Results and Discussion}

Mass Transport in Thin Films on Micropatterned Platforms. Figure 3A shows the outcome of preliminary "screening experiments": cyclic voltammograms were obtained in a $2 \mathrm{mM}$ aqueous solution of FcMeOH using either the SECM tip or a molecular-square-film covered (compound I) ITO platform as an electrode. While the voltammogram found with the SECM tip possesses the typical limiting current expected for an ultramicroelectrode, the response obtained with the film-covered platform as the working electrode is broadened and the peaks are poorly defined. The behavior, while complex, is not unexpected: the patterned overlayer of impermeable photoresist creates an array of 1000 interconnected microelectrodes (per $\mathrm{cm}^{2}$ of exposed pattern), each $8 \times 10^{-5} \mathrm{~cm}^{2}$ in area and separated by $50 \mu \mathrm{m}$ from neighboring array elements. The dominant diffusion profile (i.e., partially radial ${ }^{16}$ vs fully linear) will depend on the experimental time scale. The situation is further complicated by mass transport through the mesoporous molecular film to the underlying ITO platform, behavior that is typically described using permeation models. ${ }^{17,18}$ With these models, regardless of the form of the solution-phase mass transport, the overall current obtained at a film-covered electrode can be described as the reciprocal sum of solution and film transport rates $\left(i_{\text {solution }}\right.$ and $i_{\text {film }}$, respectively): ${ }^{17}$

$$
\frac{1}{i}=\frac{1}{i_{\text {solution }}}+\frac{1}{i_{\text {film }}}
$$

If transport within the film can be accurately described as diffusion-controlled membrane-permeation behavior, eq 1 can be expanded as ${ }^{17}$

$$
\frac{1}{i}=\frac{1}{i_{\text {solution }}}+\frac{d}{n F A P D_{\mathrm{f}} C_{\mathrm{s}}}
$$

where $n$ is the number of electrons in the oxidation/reduction reaction; $F$ is the Faraday constant; $r$ and $A$ are the radius and area of the microelectrode, respectively; $D_{\mathrm{s}}$ and $D_{\mathrm{f}}$ are the redoxprobe solution and film diffusion coefficients, respectively; $C_{\mathrm{s}}$ is the redox-probe solution concentration; $d$ is the film thickness; and $P$ is the redox probe partition coefficient $\left(=C_{\mathrm{f}} / C_{\mathrm{s}}\right)$.

During slow potential cycling (as in Figure $3 \mathrm{~A}$ ), the diffusional profiles for neighboring elements of the micropatterned array intersect, giving a response that is most accurately described by mixed linear/radial diffusion. ${ }^{19}$ The mathematical description of the $i_{\text {solution }}$ term in eq 2 , therefore, is anticipated to be complicated. Consequently, we have utilized the array voltammograms only to confirm electrical connectivity, and to determine the potentials required for SECM experiments (generator and collector electrodes ( $E_{\mathrm{g}}$ and $E_{\mathrm{c}}$, respectively); see arrows on the potential axis of Figure $3 \mathrm{~A}$ ).

Our initial studies with SECM ${ }^{10}$ focused on proof-of-concept measurements of molecular transport through a well-understood

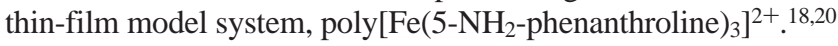
We found that the ordinarily cumbersome analysis of SECM currents can be greatly simplified by normalizing the tip current over a film-coated platform $\left(i_{\text {film }}\right)$ to the tip current above a bare platform $(i)$ and using the following equation: ${ }^{10}$

$$
\frac{i}{i_{\text {film }}}=1+\frac{4 D_{\mathrm{s}} d}{\pi r P D_{\mathrm{f}}}
$$

In this equation, $r$ is the radius of the SECM microelectrode tip. This analysis requires that the tip height above the outermost surface be identical in each experiment; one can achieve this by using the well-known tip response as it approaches an insulating surface. ${ }^{21,22}$ A typical tip approach curve for our system is shown in Figure 3B, where the SECM tip is slowly brought to within ca. $2 \mu \mathrm{m}$ of the film-covered ITO surface. The decrease in current as the tip nears the surface is a consequence of hindered diffusion to the microelectrode tip, where the potential of the tip $\left(E_{\text {tip }}\right)$ is held beyond the oxidation wave of the redox mediator $\left(E_{\text {tip }}=E_{\mathrm{g}}\right)$, and the sample platform is not electrically addressed in the cell. The current diminution is well understood, and the current response for an individual SECM tip is determined by specific geometric factors, such as its radius and the thickness of its insulating sheath. ${ }^{22}$ Using the known response for a given microelectrode tip, we are able to control the tip height above the sample surface precisely and reproducibly, making the analysis suggested by eq 3 experimentally feasible. 


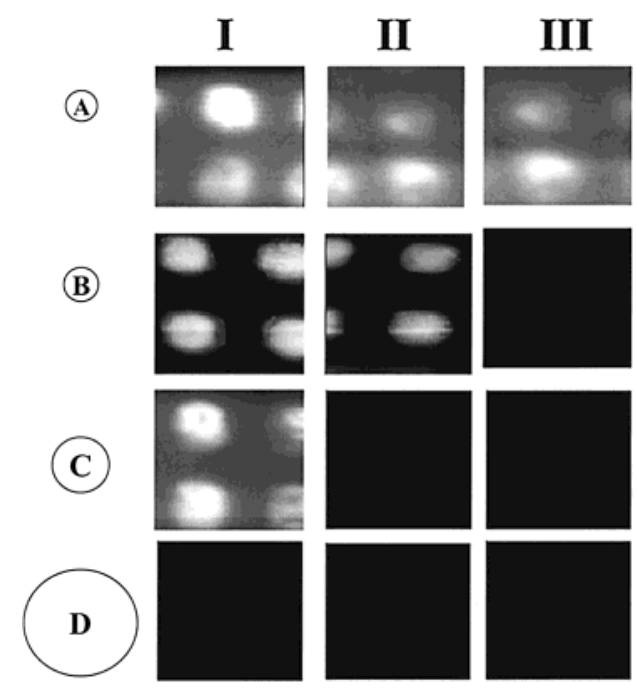

Figure 4. Scanning electrochemical microscopy images of $200 \mu \mathrm{m} \times$ $200 \mu \mathrm{m}$ areas on micropatterned ITO slides: the columns (from left to right) correspond to electrode areas featuring a thin-film overlayer of I, II, or III. The current scale in each image is from 0 to $i$, where $i$ is the SECM tip current obtained over a bare platform surface. The rows correspond to the following redox mediator solutions, applied platformelectrode potentials, and SECM tip current $i$ : (A) $2 \mathrm{mM} \mathrm{FcMeOH}$ (diameter $\sim 4.5 \AA$ ), $E_{\text {plat }}=0.5 \mathrm{~V}, i=1.2 \mathrm{nA}$; (B) $3 \mathrm{mM} \mathrm{Ru}\left(\mathrm{NH}_{3}\right)_{6}{ }^{3+}$ (diameter $\sim 5.5 \AA$ ) , $E_{\text {plat }}=-0.35 \mathrm{~V}, i=5.5 \mathrm{nA}$; (C) $5 \mathrm{mM} \mathrm{Fe}(\text { phen })_{3}{ }^{2+}$ (diameter $\sim 13 \AA$ ), $E_{\text {plat }}=1.0 \mathrm{~V}, i=3.5 \mathrm{nA}$; and (D) $10 \mathrm{mM}$ $\mathrm{Fe}\left(\text { bphen }\left(\mathrm{SO}_{3}\right)_{2}\right)_{3}{ }^{4-}($ diameter $\sim 24 \AA), E_{\text {plat }}=1.1 \mathrm{~V}, i=3.2 \mathrm{nA}$. In each case, $E_{\text {tip }}$ was fixed at $0 \mathrm{~V}$ and all solutions contained $0.1 \mathrm{M} \mathrm{KNO}_{3}$ electrolyte.

SECM Imaging of Tunable Porosity of Porphyrin-Based Molecular Squares. Figure 4 shows a series of SECM images obtained at constant tip height over a single ITO platform with regions coated with three different films. In this experiment, the micropatterned platform featured thin films of assemblies I, II, and III (Figure 2). A fourth region of the pattern remained unmodified for current normalization as required for eq 3 , above. The films were evaluated using identical experimental conditions; the resulting images shown in Figure 4 are for a series of redox probes ranging in diameter from 4.5 to $24 \AA$ (see figure caption). In these images, the brighter regions represent higher currents and correspond spatially to the molecular-film-covered holes in the photoresist pattern; the darker areas indicate zero or negligible current.

We have shown previously ${ }^{10}$ that SECM images are useful for qualitative assessment of size-selectivity, because redox probes that are excluded from a mesoporous film give no measurable redox current or discernible SECM image. To determine a thin film's molecular sieving ability, SECM imaging is performed in a "platform (or substrate) generator/tip collector" mode. Tip currents therefore arise only as a result of the redox probe permeating the sample film and reaching the underlying electrode surface, where it reacts and subsequently diffuses out of the film and into solution where it can be detected by the SECM tip; see Figure 5. From Figure 4, the patterned platform underlying the thin film of $\mathbf{I}$ is readily imaged with the three smallest redox molecules, but no current is observed using the largest probe, $\mathrm{Fe}\left(\mathrm{bphen}\left(\mathrm{SO}_{3}\right)_{2}\right)_{3}{ }^{4-}$. When the same redox probes are used to examine a film of II, no tip current and no platform images are observed with either $\mathrm{Fe}(\text { phen })_{3}{ }^{2+}$ or $\mathrm{Fe}$ (bphen$\left.\left(\mathrm{SO}_{3}\right)_{2}\right)_{3}{ }^{4-}$ as the probe. The patterned platform beneath the thin film of III can be imaged by SECM using only the smallest redox probe molecule, $\mathrm{FcMeOH}$.

We attribute the lack of current and the featureless images recorded in several of the panels in Figure 4 to complete

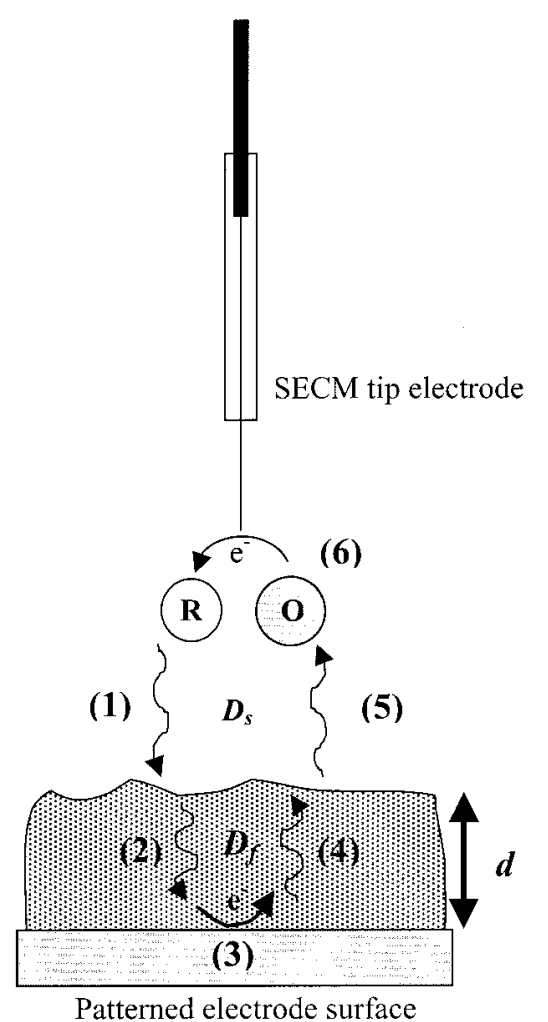

Figure 5. Schematic representation of the redox probe mass transport in the SECM "micropatterned electrode generator/tip collector" mode. (1) Diffusion in solution with diffusion coefficient $D_{\mathrm{s}}$. After partitioning across the film/solution interface (not shown) and (2) diffusing within the film (of thickness $d$ ) with diffusion coefficient $D_{\mathrm{f}}$, the probe (3) reacts with the underlying (micropatterned) electrode surface $(4,5)$, diffuses back out into solution, and finally (6) reacts at the SECM microelectrode tip to regenerate the starting material.

exclusion of the redox probes from the films included in those panels. In each case, the diameters of the excluded probes exceed those of the cavity or cavities associated with individual molecular squares, while the probes that do display structured images and significant currents are, in every case, smaller than the cavity or cavities associated with individual molecular squares. The combined findings corroborate the earlier findings, based on RDE and cyclic voltammetric measurements, that cutoffs for molecular sieving by thin films of neutral tetrarhenium squares can be quantitatively correlated with the sizes of cavities found in individual molecules and that the chemical tailoring of the cavity alters the size cutoff in a way that is predictable based on the dimensions of cavities associated with individual squares. ${ }^{3 \mathrm{~b}}$ The combined results provide very strong support for the notion that transport is controlled by passage through intramolecular cavities rather than through interstitial cavities or defect structures.

Finally, we note that the variations in current within the responsive sections of individual images in Figure 4 result from differences in film thickness. For the purposes of this experiment, the three chloroform solutions were drop-cast (rather than spin coated) to apply films to the same ITO platform, necessarily giving rise to a nonuniformly coated pattern. The variability of film thickness is easily observed in the SECM images, highlighting the sensitivity of this methodology. However, although the protocol is useful as a screening method for evaluation of size selectivity, for quantification of redox-probe permeability uniformly coated platforms were exclusively employed.

Quantification of Molecular Permeabilities. The diffusive flux of molecules through a membrane is inversely proportional 


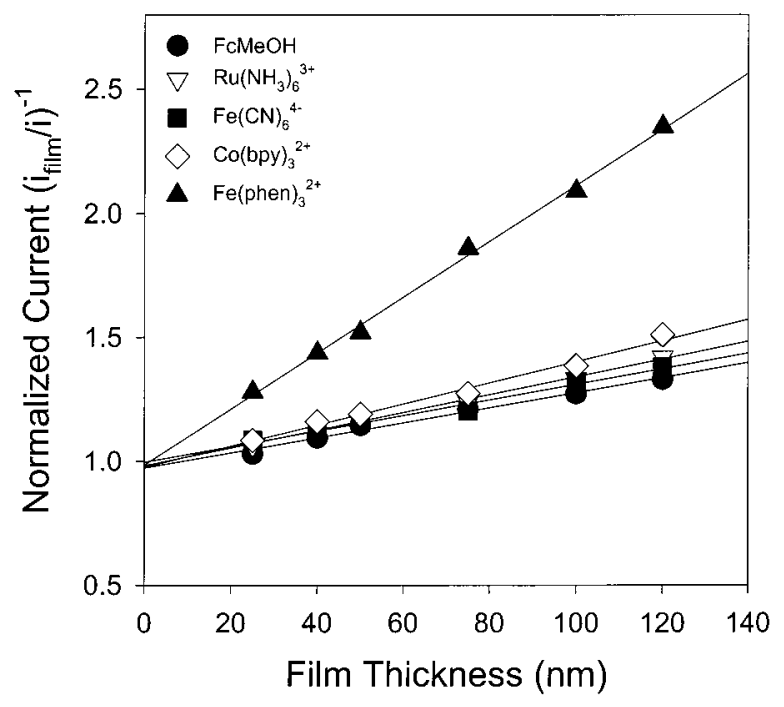

Figure 6. Plots of the normalized SECM tip current $\left(i / i_{\text {film }}\right)$ obtained for films of $\mathbf{I}$ for the indicated redox probe solutions, with linear regression. Each point represents the average of a minimum of 100 separate measurements. Note that the concentrations and solution diffusion coefficients of the five probes are not identical.

to the membrane thickness, but directly proportional to the molecule's equilibrium concentration within the film, $C_{\mathrm{f}}$, and to its film-based diffusion coefficient. For many sensing, separation, and catalysis applications, high fluxes are much more desirable than low ones. SECM is an excellent technique for quantifying the intrinsic membrane-transport properties of redoxactive permeants as measured by the molecular permeability, $P D_{\mathrm{f}}$, which is essentially the product of the normalized concentration of a compound in a film and its film-based diffusion coefficient.

By utilizing smooth, evenly coated films on the patterned ITO platforms described, we have evaluated, via eq 3, the permeability of I with respect to five redox probes. Figure 6 summarizes a large number of experiments directed toward this goal. Shown in the figure are plots of the normalized SECM tip current $\left(i / i_{\text {film }}\right)$ versus the porphyrin square film thickness. Each data point on the plot represents the average value of a minimum of 100 film-covered ITO holes (from at least two patterned platforms).

The linear regression of the plots in Figure 6 gives slopes that are described above by eq 3 and from which each redox probe's permeability can be determined. Table 1 lists the $P D_{\mathrm{f}}$ data calculated using this analysis and compares these to values previously obtained by RDE voltammetry. ${ }^{3 \mathrm{~b}}$ While the findings agree, the SECM experiment, by virtue of the large number of data points collected for each sample, clearly permits permeabilities to be much more precisely determined. ${ }^{23}$

Also reported in Table 1, but with lower precision because fewer data points were collected, are $P D_{\mathrm{f}}$ values for $\mathrm{Ru}\left(\mathrm{NH}_{3}\right)_{6}{ }^{3+}$, $\mathrm{Fe}(\mathrm{CN})_{6}{ }^{4-}$, and $\mathrm{Fc}-\mathrm{MeOH}$ transport through thin-films of II, and for $\mathrm{Fc}-\mathrm{MeOH}$ transport through thin-films of III.

Several aspects of the data merit further comment. First, while $P D_{\mathrm{f}}$ values for redox probes decrease with increasing probe diameter, there is no dependence on ionic charge, consistent with the uncharged nature of the molecular films. The exclusion of $\mathrm{Fe}\left(\mathrm{bphen}\left(\mathrm{SO}_{3}\right)_{2}\right)_{3}{ }^{4-}$ from $\mathbf{I}$ is, therefore, not an electrostatic effect, but a size effect. Second, in comparison to thin-films composed of a representative amorphous metallopolymer, poly$\left[\mathrm{Fe}(5 \text {-amino-1,10-phenanthroline })_{3}{ }^{2+}\right]\left(\mathrm{X}^{-}\right)_{2},{ }^{10}$ thin-films of $\mathbf{I}$ transport permeant molecules 2 to 25 times faster. We have previously attributed even faster transport through thin films
TABLE 1: Redox Probe Permeabilities in Thin Films of Porphyrinic Molecular Squares

\begin{tabular}{|c|c|c|c|c|}
\hline film & redox mediator & $\begin{array}{c}\text { avg } \\
\operatorname{diam}^{a} \\
(\AA)\end{array}$ & $\begin{array}{c}P D_{\mathrm{f}} \times 10^{8} \\
\left(\mathrm{~cm}^{2} / \mathrm{s}\right) \\
\mathrm{SECM}^{b}\end{array}$ & $\begin{array}{c}P D_{\mathrm{f}} \times 10^{8} \\
\left(\mathrm{~cm}^{2} / \mathrm{s}\right) \\
\mathrm{RDE}^{c}\end{array}$ \\
\hline \multirow[t]{6}{*}{ I } & $\mathrm{FcMeOH}$ & 4.5 & $14.5 \pm 0.1$ & $d$ \\
\hline & $\mathrm{Ru}\left(\mathrm{NH}_{3}\right)_{6}^{3+}$ & 5.6 & $25.0 \pm 0.1$ & $d$ \\
\hline & $\mathrm{Fe}(\mathrm{CN})_{6}^{4-}$ & 6 & $11.1 \pm 0.04$ & $13 \pm 5$ \\
\hline & $\mathrm{Co}(\mathrm{bpy})_{3}{ }^{2+}$ & 12 & $3.64 \pm 0.02$ & $4 \pm 2$ \\
\hline & $\mathrm{Fe}(\text { phen })_{3}{ }^{2+}$ & 13 & $1.89 \pm 0.03$ & $2.4 \pm 1.9$ \\
\hline & $\mathrm{Fe}\left(\mathrm{bphen}\left(\mathrm{SO}_{3}\right)_{2}\right)_{3}{ }^{4-}$ & 24 & 0 & 0 \\
\hline \multirow[t]{3}{*}{ II } & $\mathrm{FcMeOH}$ & & $9.9 \pm 0.5^{e}$ & \\
\hline & $\mathrm{Ru}\left(\mathrm{NH}_{3}\right)_{6}{ }^{3+}$ & & $18 \pm 1^{e}$ & \\
\hline & $\mathrm{Fe}(\mathrm{CN})_{6}{ }^{4-}$ & & $7.2 \pm 0.7^{e}$ & \\
\hline III & $\mathrm{FcMeOH}$ & & $6.5 \pm 0.9^{e}$ & \\
\hline
\end{tabular}

${ }^{a}$ Based on molecular modeling (HyperChem 3 ) idealizing the shape as spherical. ${ }^{b}$ Redox probe permeability, measured using scanning electrochemical microscopy, from the slope of the plots in Figure 6. ${ }^{c}$ Redox probe permeability measured by rotating disk electrode (RDE) voltammetry, from ref $3 \mathrm{~b} .{ }^{d}$ Not measured using RDE voltammetry. ${ }^{e}$ Average permeability based on $20-30$ points.

composed of smaller, non-porphyrinic molecular squares to alignment of cavities to create well-defined one-dimensional channels. ${ }^{3 b}$ In contrast to the smaller squares, evidence for microcrystallinity is lacking for films of I. Nevertheless, some degree of order could exist. Alternatively, the large solventfilled void volumes of films of I may account for the comparatively rapid transport of probe molecules. In addition, differences in solution-to-film partition coefficients may exist, although it is difficult to envision an across-the-board partitioning advantage (neutral, anionic, and cationic complexes) for molecular materials in comparison to metallopolymers. Third, there is surprisingly little cost, in terms of transport rates, for reducing the dimensions of the molecular cavities that define the sieving properties of the films: transport through thin-films of II occurs at about two-thirds the rate for equivalent thinfilms of I, while transport through thin-films of III occurs at about two-thirds the rate for equivalent films of II. An admittedly speculative interpretation is that the incorporation of an intracavity dipyridyl porphyrin to form II and, to a greater extent, the incorporation of an intracavity tetrapyridyl porphyrin to form III, leads to rigidification of the molecular square by eliminating two or four torsional degrees of freedom associated with the square's walls. Rigidification, in turn, leads to more highly ordered film microstructures. The more ordered microstructures result in less tortuous diffusional pathways and faster transport, largely offsetting decreases in transport associated with losses in void volume and decreases in cumulative "channel" cross section due to porphyrin ligand incorporation. Finally, the linearity of the data in Figure 6 implies that the mass transport mechanism for the redox permeants remains the same over this range of film thicknesses, such that even the thinnest porphyrin square films examined (ca. $25 \mathrm{~nm}$, corresponding to roughly 15 molecular monolayers) are capable of high quality molecular sieving. ${ }^{24}$ These films, of course, are the ones displaying the largest permeant fluxes.

Counterion Control of Thin-Film Transport and Analyte Electroactivity. In the electrochemical permeation experiments, the driving force for analyte transport is a chemical potential difference (concentration gradient) between the outer and inner edges of the film. The gradient is created by analyte oxidation or reduction, which necessarily diminishes the concentration at the inner edge of the film (film/electrode interface). The gradient can be made steeper, and the analyte flux greater, by employing thinner films or by increasing the concentration in the reservoir solution from which the analyte partitions. For ionically charged 


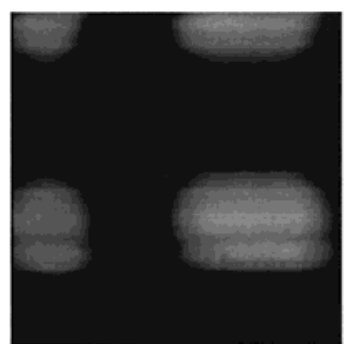

$\mathrm{NO}_{3}$

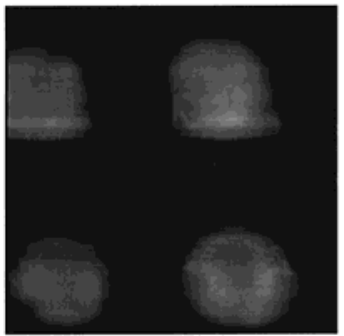

$\mathrm{CH}_{3} \mathrm{C}_{6} \mathrm{H}_{4} \mathrm{SO}_{3}$

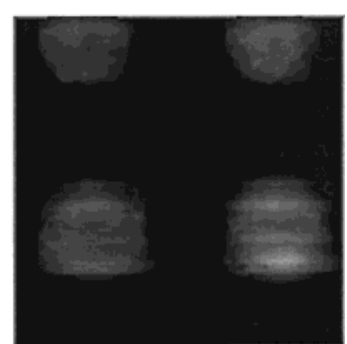

$\mathrm{SO}_{4}{ }^{2 \cdot}$

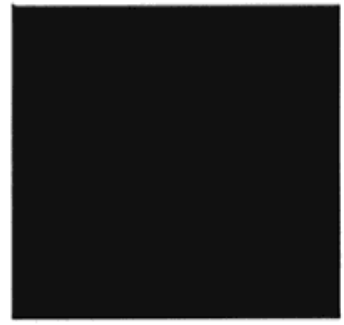

$\mathrm{Fe}\left(\mathrm{bphen}\left(\mathrm{SO}_{3}\right)_{2}\right)_{3}^{4 \cdot}$
Figure 7. SECM images of $200 \mu \mathrm{m} \times 200 \mu \mathrm{m}$ areas of a $105 \mathrm{~nm}$ thick film of $\mathbf{I}$, using $2 \mathrm{mM}$ solutions of $\mathrm{FcMeOH}$ in $0.1 \mathrm{M}$ aqueous electrolyte solutions of (A) $\mathrm{NaNO}_{3}$, (B) $\mathrm{Na}_{2} \mathrm{SO}_{4}$, (C) $\mathrm{Na}\left(\mathrm{CF}_{3} \mathrm{C}_{6} \mathrm{H}_{4} \mathrm{SO}_{3}\right)$, and (D) $\mathrm{Na}_{4}\left[\mathrm{Fe}\left(\text { bphen }\left(\mathrm{SO}_{3}\right)_{2}\right)_{3}\right]$.

analytes, the partitioning involves not only the analyte but also a charge-compensating counterion that may or may not be electroactive. (Recall that the films themselves are neutral.) If all the available counterions are sterically or otherwise excluded, the high Coulombic cost of charge separation over extended distances (say, tens of nanometers) prevents the candidate permeant ions from significantly partitioning into the film. We have exploited this phenomenon in preliminary studies previously to establish the size cutoff for permeation of thin films of pyrazine-based tetrarhenium squares by electroinactive cations. ${ }^{8 \mathrm{~b}}$ In those studies, iodide was used as an electroactive reporter anion. Its oxidation was prevented in those cases where the countercation exceeded the cavity size of the compounds comprising the film, but occurred readily when the countercation was sufficiently small to enter the film.

Here we describe a related, but more subtle phenomenon. Electrochemical oxidation or reduction requires the delivery of charge-compensating counterions in close proximity to the working electrode, eq 4.

$$
\mathrm{FcMeOH} \stackrel{-e^{-},+\mathrm{A}^{-}}{\longrightarrow} \mathrm{FcMeOH}^{+}+\mathrm{A}^{-}
$$

For an electrode in contact with a solution, this is readily accomplished with a supporting electrolyte, with overall charge balance being maintained by complementary processes occurring at the counter electrode. The same should be true with an electrode in contact with a neutral mesoporous molecular film, provided that the electrolyte can infiltrate the film. We reasoned, however, that oxidation or reduction would be blocked if chargecompensating ions were sterically precluded from entering the film.

To test the idea, we examined the oxidation of $\mathrm{FcMeOH}$ at an electrode coated with a thin film of I. Figure 7 shows SECM images obtained for a $105 \mathrm{~nm}$ thick film of $\mathbf{I}$ using a series of aqueous $\mathrm{FcMeOH}$ solutions containing supporting electrolytes consisting of $\mathrm{Na}^{+}$salts of complex anions of varying dimensions. To minimize the effects of charge migration, the electrolyte concentrations were fixed at $0.1 \mathrm{M}$. The SECM images obtained using $\mathrm{NO}_{3}{ }^{-}, \mathrm{SO}_{4}{ }^{2-}$, and $\mathrm{CF}_{3} \mathrm{C}_{6} \mathrm{H}_{4} \mathrm{SO}_{3}{ }^{-}$based

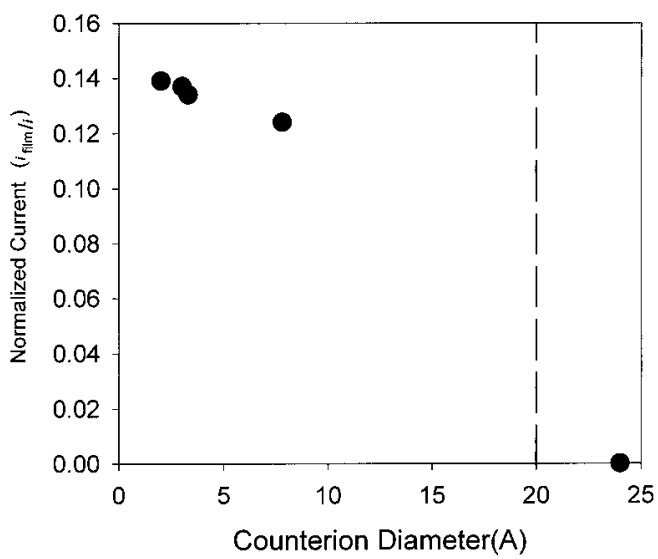

Figure 8. Plot of the normalized SECM tip current $\left(i_{\text {film }} / i\right)$ from the images in Figure 7 versus the average ionic radius of the electrolyte anion.

electrolytes (and $\mathrm{I}^{-}$, not shown) showed the characteristic pattern of the film-covered ITO platform, whereas no current or image was observed using an $\mathrm{Fe}\left(\text { bphen }\left(\mathrm{SO}_{3}\right)_{2}\right)_{3}{ }^{4-}$ based electrolyte, consistent with its steric exclusion from the thin-film coating. ${ }^{25}$ A plot of the normalized SECM tip current $\left(i_{\text {film }} / i\right)$ versus the diameter of the counteranion is shown in Figure 8, illustrating the anion size dependent cutoff of redox reactivity. ${ }^{26}$ In addition, from the figure it is evident that for those electrolyte anions that are capable of entering the film, the apparent rate of transport of $\mathrm{Fc}-\mathrm{MeOH}$ is not invariant but decreases slightly as the anion size increases. The findings illustrate that even for neutral permeants, the rate of molecular transport is convoluted to a small but detectable extent with the rate of transport of the charge-compensating ion.

With these results in hand, we also examined electrolyte control of redox-probe reactivity at an electrode coated with a thin-film of III (not shown). Consistent with the much smaller cavity size for III versus I, blockage of the oxidation of Fc$\mathrm{MeOH}$ proved possible even with sodium triflate as the electrolyte. Measurements in aqueous sodium sulfate, on the other hand, did yield an easily observed redox response from the probe molecule, but one that was significantly smaller than seen with sodium nitrate as the electrolyte, illustrating again the convolution of charge compensating ion transport with redox probe molecule transport in the electrochemical measurements.

Further experiments using a series of electrolytes featuring a common anion (chloride), but progressively larger cations $\left(\mathrm{Li}^{+}\right.$, $\mathrm{Na}^{+}, \mathrm{K}^{+}$, tetraethylammonium, tetrabutylammonium, and tetraoctylammonium ion), yielded, in every case, well-defined SECM behavior for FcMeOH transport through thin-films of III, even though the largest cations almost certainly are sterically excluded. In addition, the experiments yielded invariant $P D_{\mathrm{f}}$ values, consistent with the notion that only the chargecompensating component of the electrolyte (in this case, the anion) should influence the redox response.

Finally, note that because the reactant used for the experiments in Figures 7 and 8 is uncharged, it can permeate the film regardless of whether electrolyte ions can similarly behave. It follows that film permeation by the reactant is a necessary but not sufficient requirement for the observation of electroactivity. While we are unaware of similar demonstrations of electrolyte control over analyte electroreactivity, a related idea - electrolyte control of the redox reactivity of a film itself - has been described. Redepenning and Elliott, for example, observed that with sufficiently large charge-compensating cations, reduction of films of poly-Ru(bpy) ${ }_{3}{ }^{2+}$ could be stopped when the films 
achieved an overall neutral charge; further reduction to anionic forms was prevented because of steric exclusion of the required compensating cations. ${ }^{27}$ Lyon and co-workers observed that both oxidation and re-reduction of related films based on poly-[Fe(5amino-1,10-phenanthroline $\left.)_{3}{ }^{2+}\right]\left(\mathrm{X}^{-}\right)_{2}$ could be inhibited by incorporating charge-compensating anions, but choosing anions featuring very low film mobilities. ${ }^{28}$ Murray et al. showed that similar kinetic inhibition could be induced by employing conventional counterions, but using cryogenic temperatures to stop the intrafilm transport of charge-compensating ions. ${ }^{29}$ Finally, Smith and White showed computationally, ${ }^{30}$ and Campbell and co-workers observed experimentally, ${ }^{31}$ that the electrochemical response of a multicomponent self-assembled monolayer featuring a redox segment in close proximity to the electrode and a roughly nanometer thick dielectric segment at the monolayer/solution interface, could be completely inhibited when the outer segment blocked the uptake of chargecompensating ions.

\section{Conclusions}

Scanning electrochemical microscopy, when combined with micropatterned electrode platforms, is capable of providing reliable qualitative characterization of molecular sieving and exceptionally precise quantitative measures of molecular permeation through thin films of porphyrin-square-based meso- and microporous materials. Modification of the squares, to reduce cavity sizes and alter the size cutoff for permeation, has only a modest effect upon the permeabilities of those probe molecules small enough to pass through the modified films. Additional experiments as a function of electrolyte composition show that the ability to observe sieving behavior electrochemically is determined not only by the relative sizes of redox-active permeant molecules and film-based cavity openings but also by the steric properties of ions needed for charge compensation, even when the permeant molecule is initially neutral. As expected, when the size of the opening is altered the steric requirements for the charge-compensating ion are similarly altered. The experiments also show that charge compensating ion transport can be convoluted to a small but measurable extent with the probe molecule transport measurement. The identity of the component of the electrolyte not required for charge compensation, however, does not detectably affect the electrochemical permeation measurement.

Acknowledgment. We fondly dedicate this article to Royce Murray-teacher, scientist, and mentor. We thank A. Massari, K. Splan, and M. Merlau of Northwestern University for contributing micropatterned platforms and porphyrin compounds. We gratefully acknowledge the National Science Foundation for support of this work.

\section{References and Notes}

(1) For reviews, see: (a) Fujita, M. Chem Soc. Rev. 1998, 27, 417. (b) Leininger, S.; Olenyuk, B.; Stang, P. J. Chem. Rev. 2000, 100, 853. (c) Holliday, B. A.; Mirkin, C. A. Angew. Chem., Int. Ed. Engl., in press.

(2) For a review, see: Dinolfo, P. H.; Hupp, J. T. submitted to Chemistry of Materials.

(3) (a) Slone, R. V.; Hupp, J. T. Inorg. Chem. 1997, 36, 5422. (b) Belangér, S.; Hupp, J. T. Angew. Chem., Intl. Ed. Engl. 1999, 38, 2222.

(4) Merlau, M.; Mejia, P.; Nguyen, S. T.; Hupp, J. T., manuscript submitted.

(5) Czaplewski, K.; Snurr, R.; Hupp, J. T., unpublished results.
(6) Tzeng, B. C.; Hupp, J. T., unpublished studies.

(7) Related ideas, but involving much different materials (gold-plated channels in polymeric membranes), have been described by Martin and co-workers. See, for example: Hulteen, J. C.; Hirage, K. B.; Martin, C. R. J. Am. Chem. Soc. 1998, 120, 6603.

(8) (a) Belangér, S.; Hupp, J. T.; Stern, C. L.; Slone, R. V.; Watson, D. F.; Carrell, T. G. J. Am. Chem. Soc. 1999, 121, 557. (b) Belangér, S.; Anderson, B. C.; Hupp, J. T. Proc. Electrochem. Soc. 1999, 98-26, 208214. (c) Slone, R. V.; Benkstein, K. D.; Belangér, S.; Hupp, J. T.; Guzei, I. A.; Rheingold, A. L. Coord. Chem. Rev. 1998, 171, 221.

(9) (a) Bard, A. J.; Denault, G.; Lee, C.; Mandler, D.; Wipf, D. O. Acc. Chem. Res. 1990, 23, 357. (b) Bard, A. J.; Fan, R.-R. F.; Mirkin, M. V. In Electroanalytical Chemistry; Bard, A. J., Ed.; Marcel Dekker: New York, 1994; Vol. 18, p 243.

(10) Williams, M. E.; Stevenson, K. J.; Massari, A.; Hupp, J. T. Anal. Chem. 2000, 72, 3122.

(11) (a) Barker, A. L.; Unwin, P. R.; Amemiya, S.; Zhou, J.; Bard, A. J. J. Phys. Chem. B, 1999, 103, 7260. (b) Shao, Y.; Mirkin, M. V. J. Phys. Chem. 1998, 102, 9915.

(12) (a) Scott, E. R.; White, H. S.; Phipps, J. B. J. Membrane Sci. 1991, 58, 71. (b) Scott, E. R.; White, H. S.; Phipps, J. B. Anal. Chem. 1993, 65, 1537. (c) Bath, B. D.; Lee, R. D.; White, H. S.; Scott, E. R. Anal. Chem. 1998, 70, 1047 .

(13) Husser, O. E.; Craston, D. H.; Bard, A. J. J. Electrochem. Soc. 1989, 136, 3222.

(14) Potje-Kamloth, K.; Janata, J.; Josowicz, M. Ber. Bunsen-Ges. Phys. Chem. 1989, 93, 1480.

(15) Wightman, R. M., Wipf, D. O. In Electroanalytical Chemistry; Bard, A. J., Ed.; Marcel Dekker: New York, 1980; Vol. 15.

(16) Because the element spacing for these arrays is comparable to the element size, mixed linear/radial diffusion would be expected even at times shorter than needed for overlap of neighboring diffusion layers. At extremely short times, when the diffusion layer thickness is very small compared with the element size, linear diffusion is expected. At long times, when diffusion layers for individual array elements very strongly overlap, linear diffusion would again be expected. See, for example: Scharifker, B. R. J. Electroanal. Chem. Intl. Electrochem. 1988, 240, 61.

(17) See, for example: Gough, D. A.; Leypoldt, J. K. Anal. Chem. 1979, 51,439 .

(18) For representative electrochemical applications, see: (a) Presspich, K. A.; Maybury, S. G.; Thomas, R. E.; Linton, R. W.; Irene, E. A.; Murray, R. W. J. Phys. Chem. 1989, 93, 5568. (b) Ewing, A. G.; Feldman, B. J. Murray, R. W. J. Phys. Chem. 1985, 89, 1263.

(19) Bard, A. J.; Crayston, J. A.; Kittlesen, G. P.; Varco Shea, T.; Wrighton, M. S. Anal. Chem. 1986, 58, 2321.

(20) Belangér, S.; Stevenson, K. J.; Mudakha, S. A.; Hupp, J. T. Langmuir 1999, 15, 837.

(21) (a) Bard, A. J.; Fan, F. R. F.; Kwak, J.; Lev, O. Anal. Chem. 1989, 61, 132. (b) Kwak, J.; Bard, A. J. Anal. Chem. 1989, 61, 1221.

(22) (a) Amphlett, J. L.; Denualt, G. J. J. Phys. Chem. B 1998 102, 9946. (b) Martin, R. D.; Unwin, P. R. Anal. Chem. 1998, 70, 276.

(23) The reported uncertainties do not include uncertainties in film thickness. These, of course, are unimportant for intercomparison of transport rates for different permeants measured on the same film, but would affect the absolute precision of permeability measurements.

(24) In contrast, rates of transport through films of poly-[Fe(5-amino1, 10-phenanthroline $\left.)_{3}{ }^{2+}\right]\left(\mathrm{X}^{-}\right)_{2}$ do depart from the inverse dependence on film thickness (albeit, at thicknesses even less than the minimum thickness examined here). ${ }^{20}$

(25) Control experiments show, as expected, that $\mathrm{FcMeOH}$ oxidation is readily observable at electrodes covered with thin films of $\mathbf{I}$, even when $\mathrm{Fe}\left(\mathrm{bphen}\left(\mathrm{SO}_{3}\right)_{2}\right)_{3}{ }^{4-}$ is present in solution, provided that a smaller anion is also present.

(26) Unfortunately, other electrolyte anions examined (for example, tetraphenylborate) either lacked sufficient solubility in aqueous solutions or precipitated the electrogenerated $\mathrm{FcMeOH}^{+}$and severely complicated the electrochemistry. Consequently, counterions with diameters in the 10$20 \AA$ range are absent from the study.

(27) Elliot, C. M.; Redepenning, J. G.; Balk, E. M. J. Am. Chem. Soc. 1985, 107, 8302 .

(28) Lyon, L. A.; Ratner, M. A.; Hupp, J. T. J. Electroanal. Chem. 1995, $387,109-113$.

(29) Surridge, N. A.; Zvanut, M. E.; Keene, F. R.; Sosnoff, C. S.; Silver, M.; Murray, R. W. J. Phys. Chem. 1992, 96, 962.

(30) Smith, C. P.; White, H. S. Anal. Chem. 1992, 64, 2398-2405.

(31) Campbell, D.; Herr, B. R.; Hulteen, J. C.; Van Duyne, R. P.; Mirkin, C. A. J. Am. Chem. Soc. 1996, 118, 10211. 